\title{
Oestradiol effects on neuroendocrine responses induced by water deprivation in rats
}

\author{
Tatiane Vilhena-Franco', André Souza Mecawi2,3, Lucila Leico Kagohara Elias' \\ and José Antunes-Rodrigues ${ }^{1}$
}

${ }^{1}$ Department of Physiology, Faculty of Medicine of Ribeirao Preto, University of Sao Paulo, Ribeirao Preto, Sao Paulo, Brazil

2Department of Physiological Sciences, Institute of Biological and Healthy Sciences, Federal Rural University of Rio de Janeiro, Seropédica, Rio de Janeiro, Brazil

${ }^{3}$ Department of Physiology, Faculty of Medicine, University of Malaya, Kuala Lumpur, Malaysia

Correspondence should be addressed to T Vilhena-Franco

Email

tativilhenafranco@gmail.com

\begin{abstract}
Water deprivation (WD) induces changes in plasma volume and osmolality, which in turn activate several responses, including thirst, the activation of the renin-angiotensin system (RAS) and vasopressin (AVP) and oxytocin (OT) secretion. These systems seem to be influenced by oestradiol, as evidenced by the expression of its receptor in brain areas that control fluid balance. Thus, we investigated the effects of oestradiol treatment on behavioural and neuroendocrine changes of ovariectomized rats in response to WD. We observed that in response to WD, oestradiol treatment attenuated water intake, plasma osmolality and haematocrit but did not change urinary volume or osmolality. Moreover, oestradiol potentiated WD-induced AVP secretion, but did not alter the plasma OT or angiotensin II (Ang II) concentrations. Immunohistochemical data showed that oestradiol potentiated vasopressinergic neuronal activation in the lateral magnocellular PVN (PaLM) and supraoptic (SON) nuclei but did not induce further changes in Fos expression in the median preoptic nucleus (MnPO) or subfornical organ (SFO) or in oxytocinergic neuronal activation in the SON and PVN of WD rats. Regarding mRNA expression, oestradiol increased OT mRNA expression in the SON and PVN under basal conditions and after WD, but did not induce additional changes in the mRNA expression for AVP in the SON or PVN. It also did not affect the mRNA expression of RAS components in the PVN. In conclusion, our results show that oestradiol acts mainly on the vasopressinergic system in response to WD, potentiating vasopressinergic neuronal activation and AVP secretion without altering AVP mRNA expression.
\end{abstract}

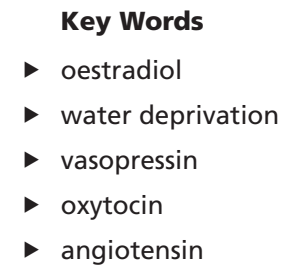

Journal of Endocrinology (2016) 231, 167-180

\section{Introduction}

Hydromineral homeostasis is a vital process in which body fluid volume and osmolality are strictly controlled by complex behavioural and systemic mechanisms (for review see: Mecawi et al. 2015). Water deprivation (WD) is an experimental model extensively used to study these responses. WD increases osmolality and decreases plasma volume, inducing the release of hormones that act to maintain homeostasis, such as vasopressin (AVP) and 
oxytocin (OT), and the activation of the renin-angiotensin system (RAS) (Windle et al. 1993, Gottlieb et al. 2006, da Silveira et al. 2007, Greenwood et al. 2015).

Changes in plasma osmolality are detected by osmosensitive neurons (osmoreceptors) located mainly in the subfornical organ (SFO) and organum vasculosum of the lamina terminalis (OVLT), two circumventricular organs (CVOs). The activation of the osmoreceptors induces AVP and OT synthesis by the magnocellular neurons of the paraventricular (PVN) and supraoptic (SON) nuclei of the hypothalamus (Oliet \& Bourque 1993, Summy-Long \& Kadekaro 2001). The SFO and OVLT have direct neural connections with SON and PVN, but the response generated by osmoreceptors may also be transmitted to these two hypothalamic nuclei through synapses in the median preoptic nucleus (MnPO) (Oldfield et al. 1991). Furthermore, AVP and OT magnocellular neurons themselves are intrinsically osmosensitive (Brown et al. 2013).

On the other hand, changes in the blood volume activate baroreceptors in the right atrium, carotid and aortic sinuses and kidneys. Afferent inputs from these sites reach the nucleus of the solitary tract (NTS) in the brainstem, which projects to SON and PVN neurons to modulate AVP neuronal activity and secretion (Share 1988, Thrasher 1994). In addition to AVP, hypovolemia is an important stimulus for ANG II release. Peripheral ANG acts on CVOs trough type $1\left(\mathrm{AT}_{1}\right)$ receptors, but the central RAS is also important in this condition because thirst response and AVP secretion can be stimulated by central or peripheral RAS (Fitzsimons 1998, Culman et al. 2001, Antunes-Rodrigues et al. 2004).

The systems that act to maintain hydromineral homeostasis can be influenced by oestradiol. It is well established that behavioural mechanisms such as thirst and sodium appetite are modulated by oestradiol (Fujisawa et al. 2001, Krause et al. 2003, Tanaka et al. 2003, Mecawi et al. 2008, Dalmasso et al. 2011).

An important piece of evidence that supports the role of oestradiol participation in hydromineral homeostasis is the expression of oestradiol receptors (ERs) in vasopressinergic and oxytocinergic neurons of the SON and PVN (Laflamme et al. 1998, Hrabovszky et al. 2004) and in other central areas that are responsive to hypertonicity/hypovolemia, such as the CVOs and the hindbrain (Shughrue et al. 1997, Voisin et al. 1997). In fact, different studies have demonstrated that oestradiol can modulate AVP secretion. However, the data in the literature show contradictory results because some reports have demonstrated a stimulatory effect of oestradiol (Skowsky et al. 1979, Barron et al. 1986, Crowley \& Amico 1993, Hartley et al. 2004), whereas others have shown that oestradiol does not induce any changes in AVP release (Crofton et al. 1985, Swenson \& Sladeck 1997). Unlike AVP, few studies have investigated the effects of oestradiol on OT secretion in the context of hydromineral balance. Amico et al. (1997) found that oestradiol and progesterone treatment did not alter OT secretion. Caligioni and Franci (2002) demonstrated that in response to osmotic stimulation, oestradiol treatment potentiates OT secretion. However, in response to feedinginduced hyperosmolality, OT secretion was reduced after oestradiol treatment (Lucio-Oliveira \& Franci 2012).

In addition to hormonal secretion, our group demonstrated that in response to hyperosmolality (Vilhena-Franco et al. 2011) or hypovolemia (Mecawi et al. 2011), AVP and OT neuronal activation in the SON and PVN are potentiated by oestradiol treatment. However, although our data and the available literature suggest that oestradiol modulates AVP and OT secretion, the precise mechanism remains poorly understood. One reason for this could be that there are no reports in the literature using a single experimental model that have evaluated how oestradiol can modulate hydromineral homeostasis from behavioural responses to hormone secretion, neuronal activation and mRNA expression. This approach is very important to understand the potential role of oestradiol in the modulation of hydromineral balance.

Thus, we evaluated the effects of oestradiol on behavioural and neuroendocrine changes induced by WD and rehydration. We hypothesized that oestradiol could modulate these responses, contributing to the maintenance of hydromineral homeostasis in response to WD.

\section{Materials and methods}

\section{Animals}

Female Wistar rats (250-280g), obtained from the Animal Facility from the campus of Ribeirao Preto, University of Sao Paulo, Brazil, were housed under 12:12 h light/dark cycle (lights on $07.00 \mathrm{~h}$ ) at $23 \pm 2^{\circ} \mathrm{C}$ with access to standard food pellets and tap water ad libitum. All experimental procedures were conducted in accordance with the Ethical Committee for Animal Use of the School of Medicine of Ribeirao Preto, University of Sao Paulo (protocol \# 064/2011). 


\section{Ovariectomy and oestradiol treatment}

Bilateral ovariectomy (OVX) was performed under 2.5\% 2.2.2-tribromoethanol anaesthesia (TBE, $1 \mathrm{~mL} / 100 \mathrm{~g}$ of body weight, i.p.). Immediately after surgery, all animals received a subcutaneous injection of oestradiol cypionate (ECP, Pfizer: $40 \mu \mathrm{g} / \mathrm{kg}, 0.1 \mathrm{~mL} / \mathrm{rat}$, s.c., OVX $+\mathrm{E}$ group) or vehicle (corn oil: $0.1 \mathrm{~mL} / \mathrm{rat}$, OVX $+\mathrm{O}$ group) once a day, for a period of seven days.

\section{Experimental design}

On the fourth day of treatment with oestradiol or vehicle, a set of rats were transferred to individual metabolic cages for adaptation, where they had free access to food and tap water and continued receiving daily hormone therapy. On the seventh day, a group of animals was subjected to $24 \mathrm{~h}$ $\mathrm{WD}$, and the animals that continued to have free access to water were considered controls. After $22 \mathrm{~h} \mathrm{WD}$, the waterdeprived animals were divided into two groups: one that remained without access to water (for a total of $24 \mathrm{~h} \mathrm{WD}$ ) and one that had water reintroduced for $2 \mathrm{~h}$. At the end of the $2 \mathrm{~h}$, the water intake was measured, and urine samples were collected to determine the urinary parameters (volume and osmolality). After this, the animals were decapitated and trunk blood (for haematocrit, osmolality and hormones measurements) and brains (for mRNA expression analysis) were collected. A second set of animals was anesthetized after the $2 \mathrm{~h}$ of reintroduction or not of water, and their brains perfused and processed for the immunohistochemistry.

\section{Hydromineral parameters}

Water intake and urinary volume were measured in volumetric burettes after $120 \mathrm{~min}$ of rehydration. Plasma and urinary osmolality were measured using an osmometer (model 5004, Precision Systems, Natick, MA, USA), based on the freezing-point method. The haematocrit was determined from trunk blood, which was collected into heparinized capillary tubes and centrifuged.

\section{Hormones measurements}

After decapitation, trunk blood was collected in chilled plastic tubes containing heparin for the measurement of the plasma AVP and OT concentrations, or peptidase inhibitors for plasma ANG II determination. Plasma AVP, OT and ANG II concentrations were measured using specific radioimmunoassays, as previously described by Husain et al. (1973), Haanwinckel et al. (1991), and Botelho et al. (1994), respectively. The assay sensitivities and intra- and inter-assay coefficients of variation were: $0.12 \mathrm{pg} / \mathrm{mL}, 3.82 \%$ and $0.74 \%$ for AVP; $0.12 \mathrm{pg} / \mathrm{mL}$, $1.72 \%$ and $10.5 \%$ for OT; $0.39 \mathrm{pg} / \mathrm{mL}, 4.34 \%$ and $11.48 \%$ for ANG II.

\section{Immunohistochemistry}

Sections were first processed for Fos immunoreactivity (anti-Fos antibody, Ab-5, rabbit, Oncogene Science, Manhasset, NY, USA, 1:10,000) followed by double labelling with either rabbit anti-OT or anti-AVP (Peninsula Laboratories, Inc., San Carlos, CA, USA, 1:20,000) using immunoperoxidase method as described in previous works (Mecawi et al. 2011, Vilhena-Franco et al. 2011). The brain nuclei analysed (SFO, dorsal division of MnPO, SON, medial and lateral magnocellular divisions of PVN) were delimited according to the Paxinos and Watson atlas (1998). Immuno-stained cells were quantified with the aid of a computerised system that includes a Leica microscope equipped with a DC 200 Leica digital camera attached to a contrast enhancement device. Representative sections from four to six animals of each experimental group from similar anatomic levels were analysed. Visual counting was performed in all sections in which the interest area was well defined anatomically and, for the SON and PVN, the counting was also done bilaterally. Finally, averages were calculated per animal and per section. The results were expressed as the percentage of AVP or OT neurons activated.

\section{Real-time polymerase chain reaction (PCR)}

Thick sections $(1500 \mu \mathrm{m})$ of PVN and SON were obtained in a cryostat from the coordinates $0.6-2.1 \mathrm{~mm}$ caudal to bregma (Paxinos \& Watson 1998). The total RNA was isolated using TRIzol reagent (Invitrogen), according to the manufacturer's instructions. 500 ng of RNA was used for cDNA synthesis using the high-capacity complementary DNA reverse transcription kit (Applied Biosystems). Semiquantitative real-time PCR was performed using the Step One Plus Real-Time PCR System (Applied Biosystems). The Taqman Gene Expression Assays (Applied Biosystems) used were: Rn00564446_g1 (OT), Rn00566449_m1 (AVP), Rn00578456_m1 ( $\left.\mathrm{AT}_{1}\right), \mathrm{Rn} 00593114 \_\mathrm{m} 1$ (Agt), Rn00561094_m1 (ACE), and Rn00667869_m1 ( $\beta$-actina). The relative mRNA expression levels were determined by 
the $2^{-\Delta \Delta C t}$ method (Livak \& Schmittgen 2001) with $\beta$-actin as an internal reference.

\section{Statistical analysis}

Data are expressed as the means \pm error (s.E.m.). The correlation analyses were performed using Linear Regression Analysis and the Pearson test. For other parameters, the evaluated analysis was performed with a two-way ANOVA test for multiple comparisons, followed by the Newman-Keuls-Student post hoc test using SigmaStat 11.0 (Systat Software, Inc., San Jose, CA, USA). The independent variables considered for analysis were the treatment (OVX $+\mathrm{E}$ and $\mathrm{OVX}+\mathrm{O}$ groups) and the $\mathrm{WD}$ (control, WD, WD $+\mathrm{H}_{2} \mathrm{O}$ ). Differences were considered significant at $P<0.05$.

\section{Results}

\section{Hydromineral parameters}

The effects of the oestradiol treatment on the hydromineral parameters are shown in Table 1 . In the $\mathrm{OVX}+\mathrm{O}$ rats, WD induced a significant increase in the water intake, which was attenuated by oestradiol treatment. Urinary volume was decreased by WD, and this could be reversed by rehydration. This response was not altered by oestradiol treatment.

WD increased the plasma and urinary osmolality in the $\mathrm{OVX}+\mathrm{O}$ rats compared with those of the respective control group, and this effect was reversed by rehydration. Oestradiol treatment did not alter the urinary osmolality in response to $\mathrm{WD}$ and rehydration compared with that of the respective OVX $+\mathrm{O}$ group. However, the increase in the plasma osmolality was attenuated by oestradiol treatment in response to WD compared with that of the vehicle treatment.

We observed that the haematocrit was increased by $\mathrm{WD}$ in the OVX $+\mathrm{O}$ rats. After rehydration, the haematocrit remained significantly elevated compared with that of the control, although this parameter was still lower than the values found in the respective WD group. Oestradiol treatment did not alter the haematocrit in response to rehydration but did decrease this parameter in the WD animals.

\section{Hormones measurements}

Figure 1 shows the effects of the oestradiol treatment on plasma AVP (A), OT (B) and ANG II (C) concentrations in WD animals subjected or not subjected to rehydration. In the $\mathrm{OVX}+\mathrm{O}$ rats, WD induced an increase in the plasma AVP, OT and ANG II concentrations, compared with those of the respective control groups. This effect of WD was reversed by rehydration for plasma AVP and OT concentrations, but ANG II remained elevated in the rehydrated animals. Oestradiol treatment potentiated WD-induced AVP release; however, did not alter the secretion of AVP in response to rehydration compared with that of the respective OVX $+\mathrm{O}$ group. For the OT and ANG II hormone release, oestradiol treatment did not induce any additional changes on these plasma hormone concentrations induced by WD or rehydration.

Table 1 Effects of oestradiol treatment on hydromineral parameters in ovariectomized (OVX) rats treated with oil (OVX $+\mathrm{O})$ or oestradiol $(\mathrm{OVX}+\mathrm{E})$ in basal conditions (CONTROL) or after water deprivation (WD) and rehydration $\left(\right.$ WD $\left.+\mathrm{H}_{2} \mathrm{O}\right)$.

\begin{tabular}{|c|c|c|c|c|c|c|}
\hline & \multicolumn{3}{|c|}{$0 V X+0$} & \multicolumn{3}{|c|}{$O V X+E$} \\
\hline & CONTROL & WD & $\mathrm{WD}+\mathrm{H}_{2} \mathrm{O}$ & CONTROL & WD & $\mathrm{WD}+\mathrm{H}_{2} \mathrm{O}$ \\
\hline $\begin{array}{l}\text { Water intake } \\
(\mathrm{mL} / 2 \mathrm{~h} / 100 \mathrm{~g} \mathrm{bw})\end{array}$ & $\begin{array}{c}n=12 \\
0.31 \pm 0.15\end{array}$ & - & $\begin{array}{c}n=10 \\
5.99 \pm 0.20^{a}\end{array}$ & $\begin{array}{c}n=13 \\
0.19 \pm 0.09\end{array}$ & - & $\begin{array}{c}n=10 \\
5.01 \pm 0.25^{\mathrm{a}, \mathrm{g}}\end{array}$ \\
\hline $\begin{array}{l}\text { Urinary volume } \\
(\mathrm{mL} / 2 \mathrm{~h} / 100 \mathrm{~g} \mathrm{bw})\end{array}$ & $\begin{array}{c}n=7 \\
0.34 \pm 0.07\end{array}$ & $\begin{array}{c}n=7 \\
0.09 \pm 0.03^{b}\end{array}$ & $\begin{array}{c}n=5 \\
0.30 \pm 0.05^{f}\end{array}$ & $\begin{array}{c}n=7 \\
0.28 \pm 0.05\end{array}$ & $\begin{array}{c}n=8 \\
0.08 \pm 0.03^{b}\end{array}$ & $\begin{array}{c}n=6 \\
0.36 \pm 0.08 \mathrm{e}\end{array}$ \\
\hline $\begin{array}{l}\text { Urinary osmolality } \\
\left(\text { mosmol/kg H} \mathrm{H}_{2} \mathrm{O}\right)\end{array}$ & $\begin{array}{c}n=9 \\
1769 \pm 87.8\end{array}$ & $\begin{array}{c}n=5 \\
2607 \pm 228^{b}\end{array}$ & $\begin{array}{c}n=6 \\
1201 \pm 133 c, d\end{array}$ & $\begin{array}{c}n=7 \\
1336 \pm 151\end{array}$ & $\begin{array}{c}n=6 \\
2678 \pm 358^{a}\end{array}$ & $\begin{array}{c}n=5 \\
1068 \pm 145^{d}\end{array}$ \\
\hline $\begin{array}{l}\text { Plasma osmolality } \\
\left.\text { (mosmol/kg H} \mathrm{H}_{2} \mathrm{O}\right) \\
\text { Haematocrit }(\%)\end{array}$ & $\begin{array}{c}n=5 \\
299 \pm 1.02 \\
n=12 \\
42.42 \pm 0.75\end{array}$ & $\begin{array}{c}n=7 \\
311 \pm 1.34^{a} \\
n=11 \\
50.09 \pm 0.69 a\end{array}$ & $\begin{array}{c}n=7 \\
299 \pm 1.47 \mathrm{~d} \\
n=13 \\
46.0 \pm 0.81^{b, d}\end{array}$ & $\begin{array}{c}n=6 \\
299 \pm 1.25 \\
n=14 \\
41.79 \pm 0.86\end{array}$ & $\begin{array}{c}n=7 \\
304 \pm 0.68 \mathrm{c}, 9 \\
n=14 \\
45.9 \pm 0.65^{a}\end{array}$ & $\begin{array}{c}n=7 \\
298 \pm 1.32 \mathrm{e} \\
n=11 \\
45.18 \pm 0.4^{\mathrm{b}, \mathrm{g}}\end{array}$ \\
\hline
\end{tabular}
with the respective WD group; $g P<0.001$ between $\mathrm{OVX}+\mathrm{O}$ and $\mathrm{OVX}+\mathrm{E}$ group.

๑ 2016 Society for Endocrinology Printed in Great Britain 


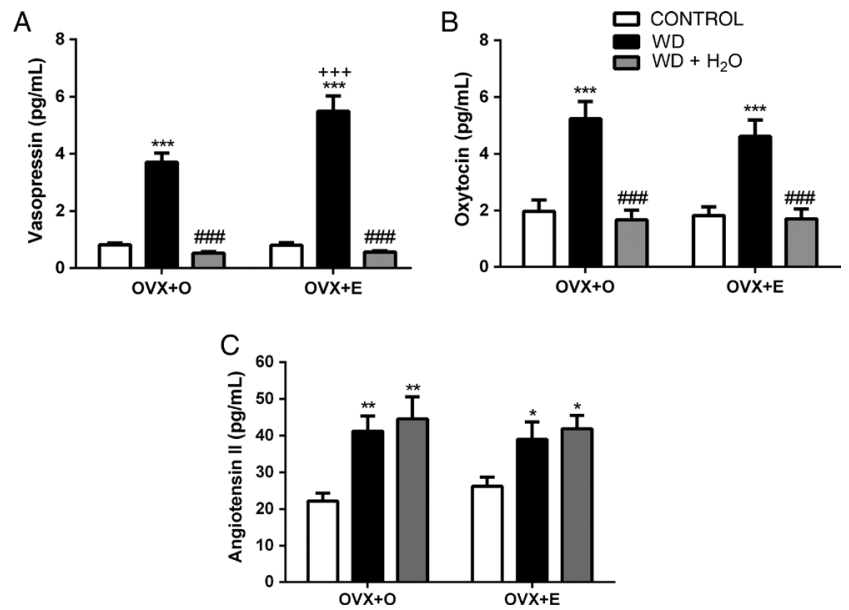

Figure 1

Effects of oestradiol treatment on plasma vasopressin (A), oxytocin (B) and angiotensin II (C) concentrations in basal conditions (CONTROL) or after water deprivation (WD) and rehydration $\left(W D+\mathrm{H}_{2} \mathrm{O}\right)$. Data are reported as means \pm S.E.M. $* P<0.05, * * P<0.01$ and $* * * P<0.001$ compared with the respective CONTROL group. \#\#P<0.001 compared with the respective WD group. ${ }^{++} P<0.001$ between ovariectomized $(O V X)$ rats treated with oil $(\mathrm{OVX}+\mathrm{O})$ and oestradiol treated group $(\mathrm{OVX}+\mathrm{E})$.

$N=14-18$ rats per group for vasopressin, 14-18 for oxytocin and 11-17 for angiotensin II.

\section{Correlation analysis}

Our data analysis demonstrated a positive correlation between the plasma osmolality and AVP (Fig. 2A) and OT (Fig. 2B) for both groups analysed. Additionally, linear regression analysis showed that the slope, which is related to the stimulus sensitivity, was greater in the oestradioltreated animals than in the vehicle-treated animals for the correlation between plasma osmolality and AVP (Fig. 2A). On the other hand, oestradiol treatment did not alter the slope for the correlation between plasma osmolality and OT (Fig. 2B).

The results also showed a positive correlation between the haematocrit and AVP levels (Fig. 2C) and OT (Fig. 2D) for both groups analysed. The slope was accentuated by oestradiol treatment only for the correlation between the haematocrit and AVP (Fig. 2C). The haematocrit/ OT correlation was not altered by oestradiol treatment compared with vehicle (Fig. 2D).

\section{Immunohistochemistry}

The effects of oestradiol treatment on the number of Fos positive nuclei in the MnPO and SFO are shown in Figs 3B and $4 \mathrm{~B}$, respectively. The results show that in the OVX $+\mathrm{O}$ rats, WD induced an increase in the number of Fosimmunoreactive neurons in the MnPO and SFO compared with those of the respective control groups. This effect

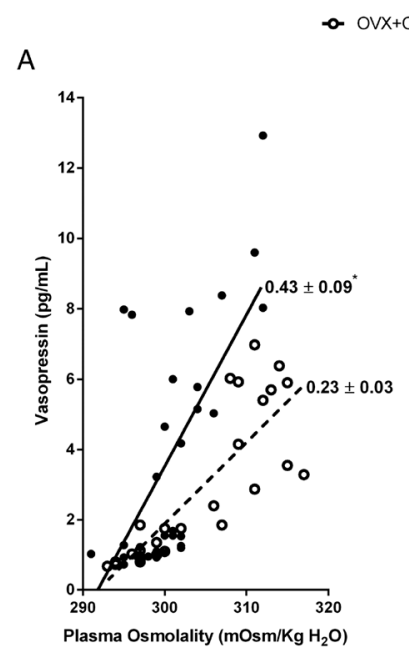

$\rightarrow$ OVX+E

B

C

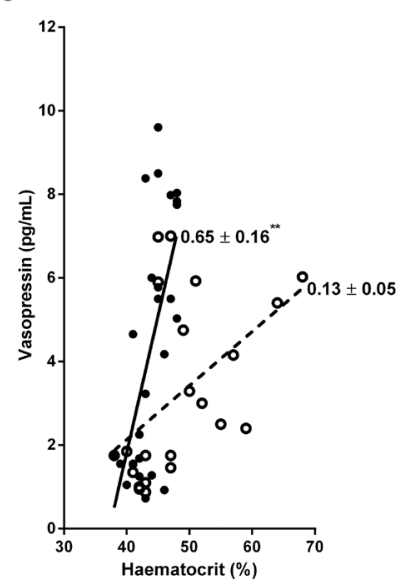

D

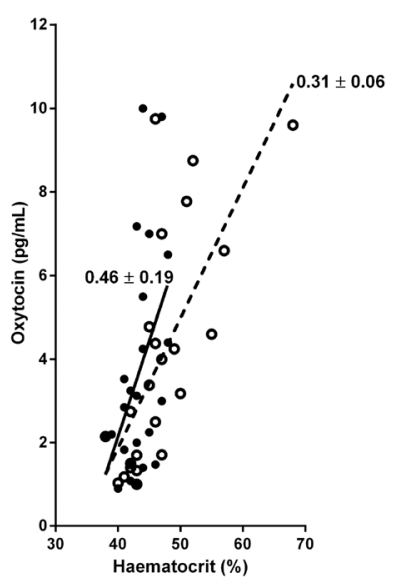

Figure 2

Correlation between plasma osmolality and vasopressin (A) and oxytocin (B) or between haematocrit and vasopressin (C) and oxytocin (D) in ovariectomized $(O V X)$ rats treated with oil $(O V X+O)$ or oestradiol $(\mathrm{OVX}+\mathrm{E})$ and submitted to water deprivation. Pearson correlation analysis was: $\mathrm{OVX}+\mathrm{O}: r=0.83, P<0.001 ; \mathrm{OVX}+\mathrm{E}: r=0.65, P<0.001$ for plasma osmolality and AVP; OVX $+\mathrm{O}: r=0.69, P<0.001$; OVX $+\mathrm{E}: r=0.50$, $P<0.01$ for plasma osmolality and OT; OVX $+\mathrm{O}: r=0.48, P<0.05$; OVX $+\mathrm{E}$ : $r=0.65, P<0.001$ for the haematocrit and AVP; OVX+O: $r=0.71, P<0.001$; OVX $+\mathrm{E}: r=0.46, P=0.024$ for the haematocrit and OT. The slope values comparing $\mathrm{OVX}+\mathrm{O}$ and $\mathrm{OVX}+\mathrm{E}$ are demonstrated in the figure.

could be reversed by rehydration in the MnPO, but not in the SFO. Oestradiol treatment did not change the response induced by WD in the MnPO and SFO or after rehydration compared with those of OVX $+\mathrm{O}$. Representative coronal sections showing the pattern of Fos-immunoreactivity in the MnPO and SFO of the different groups are presented in Figs $3 \mathrm{~A}$ and $4 \mathrm{~A}$, respectively.

The effects of oestradiol treatment on vasopressinergic neuronal activation in the SON, PaLM and PaMM of WD rats receiving or not receiving water are shown in Figs $5 \mathrm{~B}, 6 \mathrm{~B}$ and $7 \mathrm{~B}$, respectively. In the $\mathrm{OVX}+\mathrm{O}$ rats, 
A

A ovx+o

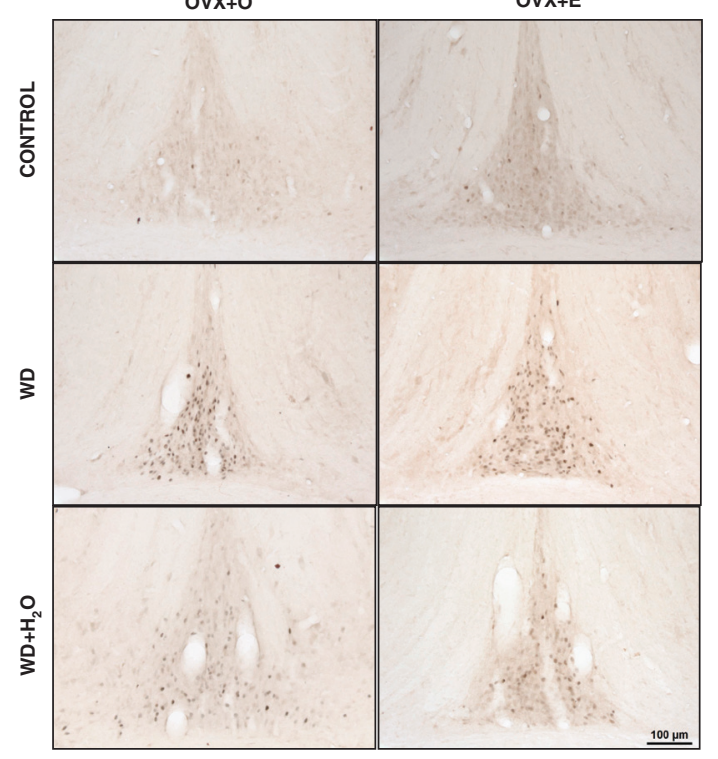

B

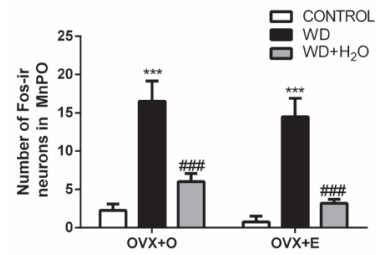

WD induced an increase in the percentage of Fos-AVP double-labelled neurons activated in the SON, PaLM, and PaMM compared with those of the respective control group. This effect was reversed by rehydration in all hypothalamic nuclei analysed. Oestradiol treatment did not modify the vasopressinergic neuronal activation in response to rehydration. On the other hand, in response to $\mathrm{WD}$, oestradiol potentiated the percentage of Fos-AVP double-labelled neurons activated in the SON and in the PaLM, compared with those of the vehicle, but not in the PaMM. Representative coronal sections showing the pattern of Fos-AVP immunoreactivity in the SON,

\section{Figure 3}

(A) Representative photomicrographs of coronal sections showing Fos-immunoreactivity in the Median Preoptic Nucleus (MnPO), under basal conditions (CONTROL) or after water deprivation (WD) and rehydration $\left(W D+\mathrm{H}_{2} \mathrm{O}\right)$, in rats pretreated with vehicle $(\mathrm{OVX}+\mathrm{O})$ or oestradiol $(\mathrm{OVX}+\mathrm{E})$. The panels are represented by $\mathrm{X} 20$ objective. (B) Effects of oestradiol treatment on the number of Fos-immunoreactive (ir) neurons in the MnPO. Data are reported as means \pm S.E.M. $* * * P<0.001$ compared with the respective CONTROL group. \#\#\#<0.001 compared with the respective WD group. $N=04-06$ rats per group.

PaLM and PaMM of the different groups are presented in Figs 5A, 6A and 7A, respectively.

Oxytocinergic neuronal activation is shown in Fig. 8. The results demonstrated a significant increase in the percentage of Fos-OT double-labelled neurons activated by WD in the SON (Fig. 8A), PaLM (Fig. 8B) and PaMM (Fig. 8C) compared with those of the respective control groups. The effect of WD could be reversed by rehydration. However, unlike for AVP, oxytocinergic neuronal activation was not altered by oestradiol treatment in response to WD in all hypothalamic nuclei analysed. Representative coronal sections showing the pattern of

A

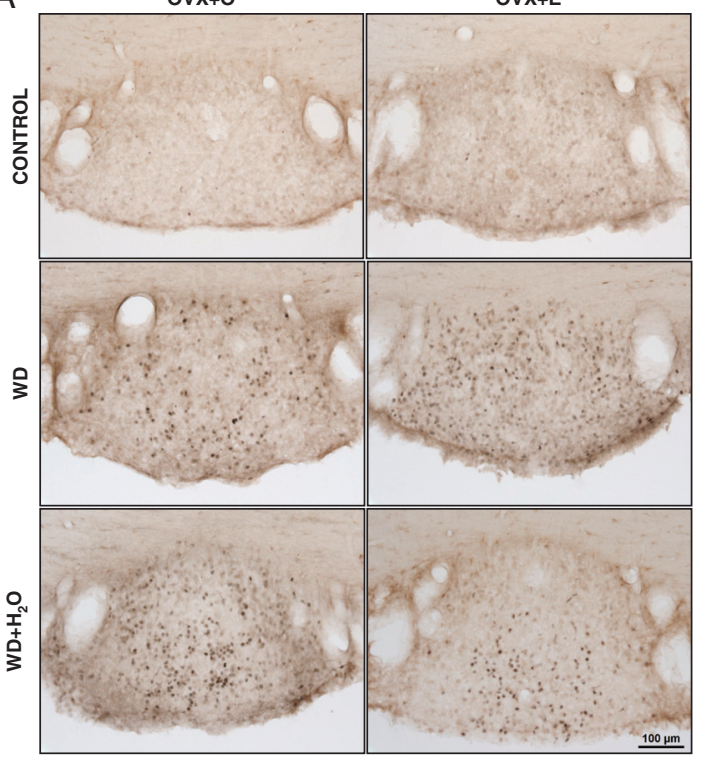

B

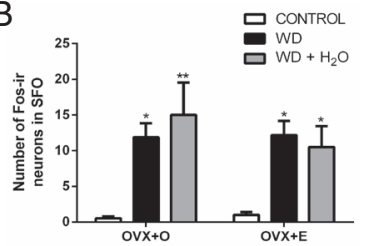

Figure 4

(A) Representative photomicrographs of coronal sections showing Fos-immunoreactivity in the Subfornical Organ (SFO), under basal conditions (CONTROL) or after water deprivation (WD) and rehydration $\left(W D+\mathrm{H}_{2} \mathrm{O}\right)$, in rats pretreated with vehicle $(O V X+O)$ or oestradiol $(O V X+E)$.

The panels are represented by $\mathrm{X} 20$ objective. (B) Effects of oestradiol treatment on the number of Fos-immunoreactive (ir) neurons in the SFO. Data are reported as means \pm S.E.M. ${ }^{*} P<0.05$ and $* * P<0.01$ compared with the respective CONTROL group. $N=04-06$ rats per group. http://joe.endocrinology-journals.org DOI: $10.1530 / J O E-16-0311$
๑) 2016 Society for Endocrinology Printed in Great Britain 
A
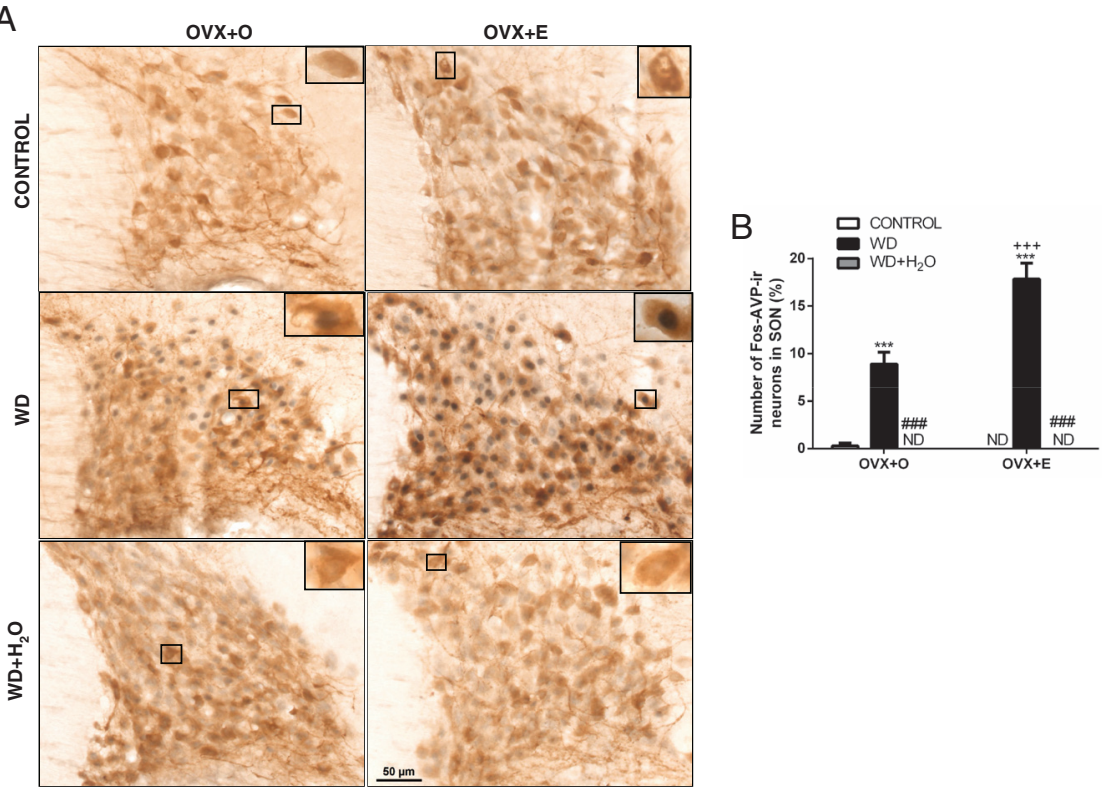

Figure 5

(A) Representative photomicrographs of coronal sections showing Fos-AVP immunoreactivity in the Supraoptic Nucleus (SON), under basal conditions (CONTROL) or after water deprivation $(W D)$ and rehydration $\left(W D+\mathrm{H}_{2} \mathrm{O}\right)$, in rats pretreated with vehicle $(\mathrm{OVX}+\mathrm{O})$ or oestradiol $(\mathrm{OVX}+\mathrm{E})$. The panels are represented by $\mathrm{X} 40$ objective. In detail, the cytoplasmic AVP label or a Fos-AVP double-labeled cell is represented by X100 objective. (B) Effects of oestradiol treatment on the number of Fos-AVP-immunoreactive (ir) neurons in the SON. Data are reported as means \pm S.E.M. ${ }^{* * *} P<0.001$ compared with the respective CONTROL group. \#\#P<0.001 compared with the respective WD group. ${ }^{+++} P<0.001$ between $\mathrm{OVX}+\mathrm{O}$ and $\mathrm{OVX}+\mathrm{E}$ group. $\mathrm{N}=04-06$ rats per group.

Fos-OT immunoreactivity in the SON, PaLM and PaMM of the different groups are presented in the Supplementary Figs 1, 2 and 3, see section on supplementary data given at the end of this article, respectively.

\section{Real-time polymerase chain reaction (PCR)}

The effects of oestradiol treatment on AVP mRNA expression in the SON and PVN, under basal conditions and after $\mathrm{WD}$, are shown in Fig. 9A and $\mathrm{B}$, respectively. The results show that in $\mathrm{OVX}+\mathrm{O}$ rats, WD induced an increase in AVP mRNA expression in the SON and PVN compared with those of the respective control groups. Oestradiol treatment did not alter this response for the SON and PVN.

Unlike for AVP, the OT mRNA expression was not altered by WD in the SON (Fig. 9C) or PVN (Fig. 9D), in $\mathrm{OVX}+\mathrm{O}$ rats. However, oestradiol treatment increased OT mRNA expression in the SON (Fig. 9C) and PVN (Fig. 9D) under basal conditions and after WD.

Regarding the mRNA expression of RAS components, we verified that the mRNA relative expression of angiotensinogen (Agt), angiotensin converting enzyme (ACE) and $\mathrm{AT}_{1}$ show a similar response profile.
A

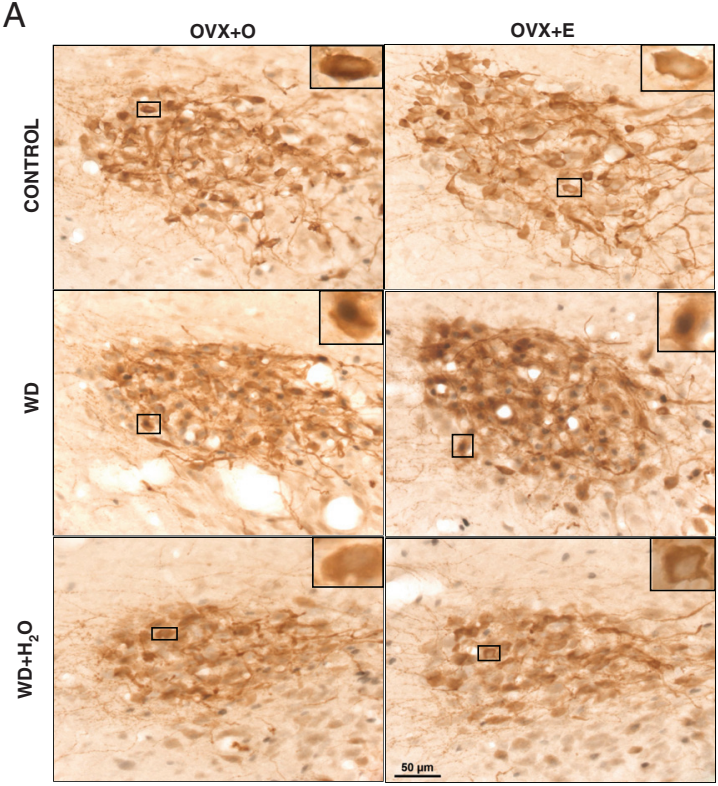

http://joe.endocrinology-journals.org DOI: $10.1530 / J O E-16-0311$
() 2016 Society for Endocrinology Printed in Great Britain

\section{Figure 6}

(A) Representative photomicrographs of coronal sections showing Fos-AVP immunoreactivity in the Lateral Magnocellular subdivision of the Paraventricular Nucleus (PaLM), under basal conditions (CONTROL) or after water deprivation (WD) and rehydration (WD $\left.+\mathrm{H}_{2} \mathrm{O}\right)$, in rats pretreated with vehicle $(\mathrm{OVX}+\mathrm{O})$ or oestradiol $(O V X+E)$. The panels are represented by $X 40$ objective. In detail, the cytoplasmic AVP label or a Fos-AVP double-labeled cell is represented by X100 objective. (B) Effects of oestradiol treatment on the number of Fos-AVP-immunoreactive (ir) neurons in the PaLM. Data are reported as means \pm S.E.M. $* * * P<0.001$ compared with the respective CONTROL group. \#\#P<0.01 and $\# \# P<0.001$ compared with the respective WD group. ${ }^{++} P<0.001$ between $\mathrm{OVX}+\mathrm{O}$ and $\mathrm{OVX}+\mathrm{E}$ group. $N=04-06$ rats per group. 
A

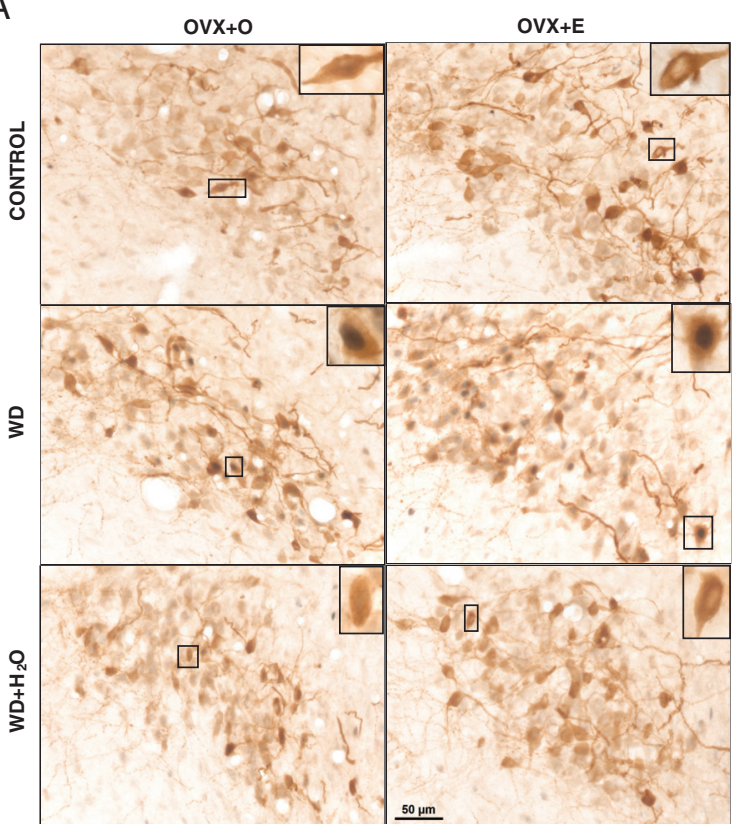

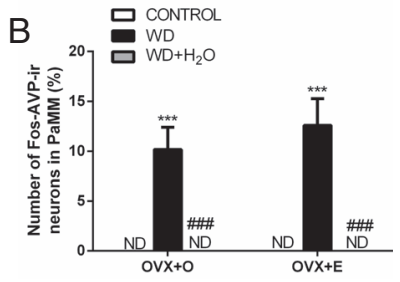

Figure 7

(A) Representative photomicrographs of coronal sections showing Fos-AVP immunoreactivity in the Medial Magnocellular subdivision of the Paraventricular Nucleus (PaMM), under basal conditions (CONTROL) or after water deprivation (WD) and rehydration $\left(\mathrm{WD}+\mathrm{H}_{2} \mathrm{O}\right)$, in rats pretreated with vehicle $(\mathrm{OVX}+\mathrm{O})$ or oestradiol $(\mathrm{OVX}+\mathrm{E})$.

The panels are represented by $\mathrm{X} 40$ objective. In detail, the cytoplasmic AVP label or a Fos-AVP double-labeled cell is represented by X100 objective. (B) Effects of oestradiol treatment on the number of Fos-AVP-immunoreactive (ir) neurons in the PaMM. Data are reported as means \pm s.E.M. $* * * P<0.001$ compared with the respective CONTROL group. \#\#\# $P<0.001$ compared with the respective WD group. $N=04-06$ rats per group.
In the $\mathrm{OVX}+\mathrm{O}$ rats, WD induced a significant increase in the Agt (Fig. 10A), ACE (Fig. 10B) and $\mathrm{AT}_{1}$ (Fig. 10C) mRNA expression compared with those of the respective control groups. Oestradiol treatment did not induce any additional changes in the mRNA expression for any of the analysed genes compared with those of the respective vehicle-treated groups.
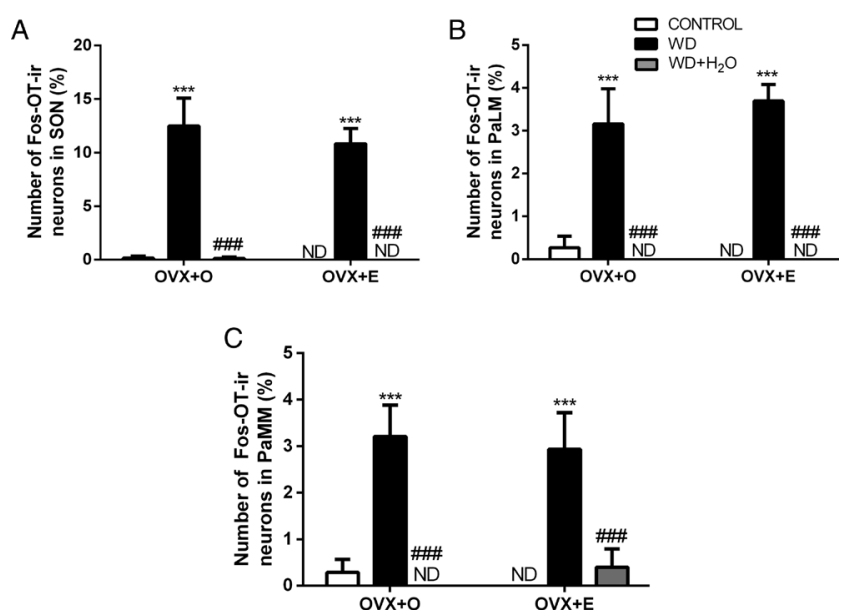

Figure 8

Effects of oestradiol treatment on the number of Fos-OT-immunoreactive (ir) neurons in the SON (A), PaLM (B) and PaMM (C). Data are reported as means \pm S.E.M. ${ }^{* * *} P<0.001$ compared with the respective CONTROL group. $\# \# P<0.001$ compared with the respective WD group. $N=04-06$ rats per group.

\section{Discussion}

Our study demonstrates that oestradiol participates in the maintenance of hydromineral homeostasis in response to WD. Importantly, this work also suggests that this modulation occurs preferentially on the vasopressinergic system.
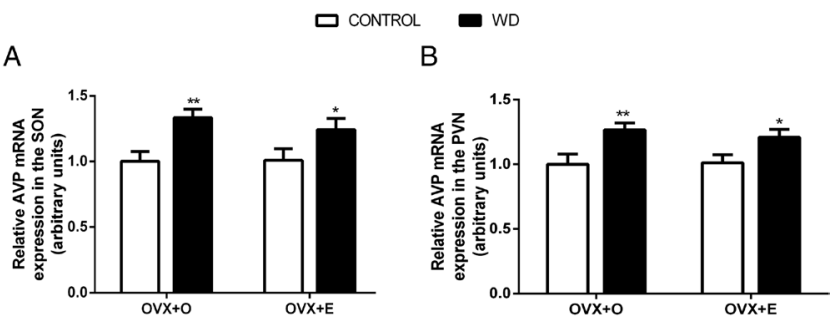

C

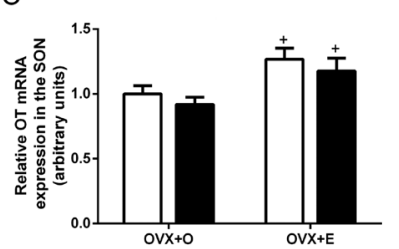

$\mathrm{D}$

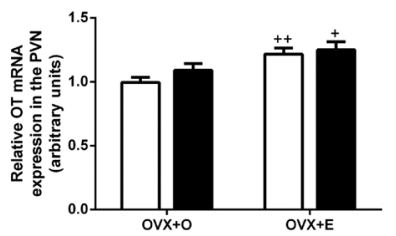

Figure 9

Effects of oestradiol treatment on vasopressin(AVP) (A and B) and oxytocin (OT) (C and D) mRNA expression in the supraoptic nucleus (SON) and paraventricular nucleus (PVN) in basal conditions (CONTROL) or after water deprivation (WD), in animals treated with vehicle $(O V X+O)$ or oestradiol $(O V X+E)$. Data are reported as means \pm S.E.M. ${ }^{*} P<0.05$, ${ }^{*} P<0.01$ compared with the respective CONTROL group. ${ }^{+} P<0.05$, ${ }^{++} P<0.01$ between $\mathrm{OVX}+\mathrm{O}$ and $\mathrm{OVX}+\mathrm{E}$ treated groups. $N=11-14$ rats per group.

Published by Bioscientifica Ltd. 
A

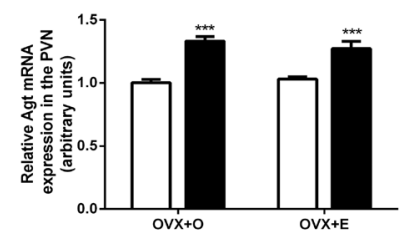

B

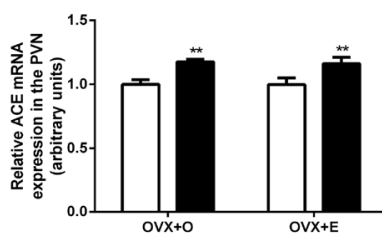

C

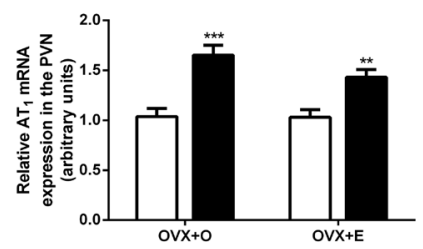

\section{Figure 10}

Effects of oestradiol treatment on angiotensinogen (Agt) (A), angiotensin converting enzyme (ACE) (B) and angiotensin II receptor, type I (AT, receptors) (C) mRNA expression in the paraventricular nucleus (PVN) in basal conditions (CONTROL) or after water deprivation (WD), in animals treated with vehicle $(\mathrm{OVX}+\mathrm{O})$ or oestradiol $(\mathrm{OVX}+\mathrm{E})$. Data are reported as means \pm S.E.M. ${ }^{* *} P<0.01, * * * P<0.001$ compared with the respective CONTROL group. $N=06$ rats per group for Agt; $12-13$ rats per group for $A C E ; 13-15$ rats per group for $A_{1}$.

Previous studies in the literature that have investigated the role of oestradiol on hydromineral balance have not explored in a single experimental model if oestradiol is capable to modulate different components of the response triggered by dehydration, like thirst, hormone secretion, neuronal activation and mRNA expression. This approach is very important to understanding how oestradiol contributes to maintain hydromineral homeostasis. Another important point is that oestrogen receptors are expressed in both, hyperosmolality (Shughrue et al. 1997, Voisin et al. 1997) and hypovolemia sensing structures in the brain (Shughrue et al. 1997, Simonian \& Herbison 1997). Thus, it is important to use an experimental model that recruits these two adaptive responses. In this context, different to other experimental models, WD activates these two pathways. For example, haemorrhage induces extracellular dehydration activating pathways that respond to hypovolemia, like NTS and activation of RAS, but does not involve osmoreceptor response. Infusion of hypertonic saline induces intracellular dehydration that triggers osmoreceptor in the CVOs, but does not evoke RAS activation. Different from these models, WD induces both, extracellular and intracellular dehydration, activating osmoreceptors and pathways related to volume control.

This experimental condition is validated by our data, which demonstrate that WD induces an increase in the haematocrit, urinary and plasma osmolality, and a decrease in the urinary volume of $\mathrm{OVX}+\mathrm{O}$ rats. To restore homeostasis, thirst and an increase in AVP, OT, and ANGII release was observed, data that are consistent with earlier, well-established data from studies performed in male rats (Windle et al. 1993, Huang et al. 1996, Stricker \& Sved 2002, Gottlieb et al. 2006, Greenwood et al. 2015). Additionally, our study suggests that these mechanisms could be modulated by oestradiol.

Regarding the effects of oestradiol on water intake, our results corroborate previous observations from Krause et al. (2003) and Mecawi et al. (2008), who showed that oestradiol reduces WD-induced water intake. It has also been demonstrated that in addition to WD, oestradiol reduces water intake stimulated by other experimental models that increase ANG II plasma levels, such as hypovolemia and hypotension (Krause et al. 2003, Mecawi et al. 2008, Araujo et al. 2013). Thus, taken together, these studies suggest that oestradiol reduces water intake through an action on RAS.

It is well established that ANG II produced peripherally induces water intake by binding to its $\mathrm{AT}_{1}$ receptors in CVOs, specifically in the SFO (Fitzsimons 1998, Culman et al. 2001). Since $\mathrm{AT}_{1}$ receptors are stimulated, it promotes the activation of central pathways that trigger water intake behaviour. Thus, the inhibitory effect of oestradiol on water intake could occur by inhibiting the production of peripheral ANG II or by direct central action, since oestradiol receptors are expressed in the $\mathrm{SFO}$ and are co-localized with $\mathrm{AT}_{1}$ in this area (RosasArellano et al. 1999). In this context, Krause et al. (2003) demonstrated that oestradiol reduces water intake induced by isoproterenol ( $\beta$-adrenergic agonist that activates RAS) without changing the peripheral synthesis of Ang II. Furthermore, oestradiol was shown to decrease $\mathrm{AT}_{1}$ mRNA expression in the SFO (Kisley et al. 1999, Krause et al. 2006). Thus, these data from the literature suggest that oestradiol reduces water intake by a central mechanism, decreasing ANG II action in the SFO. Our results further support these data showing that, in response to $\mathrm{WD}$, oestradiol treatment decreases water intake but does not alter plasma ANG II concentrations.

We also observed that $\mathrm{AT}_{1}, \mathrm{ACE}$ and Agt mRNA expression in the PVN increased in response to $\mathrm{WD}$; however, this response was not changed by oestradiol treatment. These results suggest that oestradiol's action on hydromineral homeostasis in response to WD seems not to involve the RAS activation because both ANG II peripheral release and RAS component mRNA expression in PVN are unaffected by oestradiol.

Published by Bioscientifica Ltd 
Oestradiol treatment potentiated AVP secretion but did not alter the OT plasma levels in response to WD. Previous reports in the literature have shown that oestradiol may modulate AVP and OT secretion under diverse experimental conditions (Skowsky et al. 1979, Amico et al. 1981, 1995, 1997, Crofton et al. 1985, Barron et al. 1986, Crowley \& Amico 1993, Hartley et al. 2004, Swenson \& Sladeck 1997, Caligioni \& Franci 2002, Mecawi et al. 2011, Vilhena-Franco et al. 2011). However, the involvement of oestradiol on AVP and OT secretion in response to WD has not yet been investigated in the literature in animal models. Therefore, our results suggest for the first time that oestradiol may contribute to the maintenance of hydromineral homeostasis in WD conditions, specifically enhancing AVP secretion and thereby facilitating the appropriate homeostatic adjustments in response to dehydration. This oestradiolspecific action on AVP secretion in response to WD may underlie the attenuated plasma osmolality and haematocrit elevation in this condition, which probably occur through water conservation induced by AVP. Body fluid retention has been attributed to oestradiol in diverse experimental conditions (Davison et al. 1984, Veille et al. 1986, Stachenfeld \& Taylor 2004). Considering that AVP is the main hormone involved in renal water reabsorption, it is plausible to suggest that AVP could mediate this fluid retention induced by oestradiol. However, our data also demonstrated that although oestradiol increases AVP secretion in water-deprived animals, it does not alter the urinary volume or osmolality in this experimental condition. In this regard, in a study performed in women, Stachenfeld et al. (1998) showed that oestradiol treatment increased AVP secretion but also reduced the fractional excretion of sodium. This finding could explain our results because the sodium retention induced by oestradiol could be counteracting the AVP effect in the kidney, preventing alterations in urinary osmolality. Other previous studies have also suggested that oestradiol's effects on the sodium balance may contribute to the fluid retention induced by this hormone (Aitken et al. 1974, Barron et al. 1986).

Our results also demonstrated that the slope of the correlation between plasma osmolality and the haematocrit with AVP was significantly steeper in the oestradiol-treated OVX rats. This effect was not observed for OT. This implicates that oestradiol increases the sensitivity for AVP release in response to hyperosmolality and hypovolemia induced by WD. These data support the oestradiol effect potentiating preferentially the AVP secretion, but not OT secretion. Moreover, these data also suggest that in response to $\mathrm{WD}$, osmoregulatory mechanisms and pathways related to volume and blood pressure controlling AVP secretion are subject to oestradiol action. Regarding the correlation between plasma osmolality and AVP, similar results are shown in studies performed in humans treated with acute infusion of hypertonic $\mathrm{NaCl}$ solution (Stachenfeld et al. 1998, Stachenfeld \& Keefe 2002) but, in this case, oestradiol altered the threshold for AVP release but not the slope. They observed that oestradiol reduced the threshold for AVP release, indicating that smaller increase in plasma osmolality is sufficient to trigger AVP release. Our results showed a modulation by oestradiol changing the slope of the correlation between the plasma osmolality and AVP concentration, indicating a greater sensitivity in the osmoreception under oestradiol treatment.

In addition to stimulating hormone secretion, WD also promotes neuronal activation in the SON, PVN, and CVOs (Morien et al. 1999, De Luca et al. 2002, Gottlieb et al. 2006, Dalmasso et al. 2015). In this regard, we showed that the number of Fos immunoreactive neurons is enhanced by WD in the SFO and MnPO, as well as in the vasopressinergic and oxytocinergic neurons of the SON and PVN. This effect was reversed by rehydration in the SON, PVN and MnPO but was not altered in the SFO. Consistent with our findings, De Luca et al. (2002) observed that Fos immunoreactivity in the SFO was not altered by rehydration. These authors suggested that the maintenance of neuronal activation in the SFO is crucial to the sodium appetite, which is triggered after WD by the action of ANG II. In fact, we observed that neither ANG II peripheral release nor SFO neuronal activation were not restored by rehydration.

We have also demonstrated that oestradiol replacement did not alter the neuronal activation in the CVOs or the oxytocinergic neuronal activation induced by WD; however, in this experimental condition, it potentiated vasopressinergic neuronal activation in the SON and PaLM. These data were correlated with the effects of oestradiol on the AVP secretion. To this end, Hartley et al. (2004) showed that oestradiol increased the number of Fos positive cells in the SON after hyperosmolality or hypovolemia; however, this study did not investigate the neuron phenotype involved in this response. Recent data from our group demonstrated that vasopressinergic neurons of the SON and PVN are modulated by oestradiol in response to hyperosmotic hypervolemia (induced by extracellular volume expansion) and hypovolemia (induced by haemorrhage) (Mecawi et al. 2011, VilhenaFranco et al. 2011). Thus, the present findings provide further evidence of the stimulatory role of oestradiol on

Published by Bioscientifica Ltd 
AVP secretion and vasopressinergic neuronal activation in response to the hypertonicity and hypovolemia.

Regarding gene expression, we observed that oestradiol did not alter the AVP mRNA expression induced by WD in the SON or PVN. On the other hand, the OT mRNA expression was significantly increased by oestradiol treatment in these hypothalamic nuclei. Specifically regarding OT, studies have shown that OT mRNA expression in the SON and PVN increases in different situations related to reproductive behaviour, such as during puberty (Miller et al. 1989), oestrous (Van Tol et al. 1988), gestation (Van Tol et al. 1988, Zingg et al. 1989) and lactation (Van Tol et al. 1988, Crowley et al. 1993). In general, these studies have demonstrated a stimulatory effect of oestradiol on OT mRNA expression in the SON and PVN, which would explain the results presented here.

However, the effects of oestradiol treatment on AVP and OT mRNA expression in response specifically to hydromineral challenge have not been yet described. Crowley and Amico (1993) evaluated the effects of salt loading on OT and AVP mRNA expression in the SON and PVN in male and female rats; but, the effects of oestradiol treatment were not investigated in this case. However, an important observation from this study was that osmotic stimulation produces two effects on AVP gene expression in intact female rats, increasing both the abundance and transcript size. The increase in the transcript size preceded the changes in the absolute quantity in AVP mRNA, which could suggest that oestradiol participates in the post-transcriptional AVP mRNA expression. Studies performed in male rats (Carrazana et al. 1988, Carter \& Murphy 1991) show that this increase in the size of AVP mRNA in response to osmotic stimulation is attributed to a lengthening of the mRNA poly (A) tail. It was also demonstrated that the control of the quantity of mRNA produced and of the poly (A) tail length may be mediated independently (Carter \& Murphy 1989). Together, these data indicate that although we did not observe any alterations in the quantity of the AVP mRNA induced by oestradiol, we cannot exclude the possibility that oestradiol action affects AVP mRNA at the structural level in response to WD. However, a crucial point in our study is to demonstrate for the first time that the effect of oestradiol on vasopressinergic neuronal activation and AVP secretion occurs independently of mRNA expression of this neuropeptide.

It has been proposed that the modulation exerted by oestradiol on AVP magnocellular activity could occur through a direct mechanism. This hypothesis is supported by evidence showing that vasopressinergic neurons in the SON and PVN express ER- $\beta$ (Laflamme et al. 1998, Hrabovszky et al. 2004). A second mechanism that has been suggested by literature is an indirect action through osmosensitive neurons in the CVOs, based on the evidence that the ER- $\alpha$ is expressed in these areas (Voisin et al. 1997, Shughrue et al. 1997). In this context, our data demonstrate that vasopressinergic magnocellular activity is potentiated by oestradiol, indicating that oestradiol can directly modulate the activity of these neurons. Moreover, we also observed that oestradiol did not change neuronal activation in the MnPO or SFO of WD rats, suggesting that oestradiol could act mainly on AVP neurons in response to hyperosmolality induced by WD.

Furthermore, because we observed that oestradiol treatment did not alter the mRNA expression of AVP but instead increased the sensitivity to AVP secretion in response to hyperosmolality induced by $\mathrm{WD}$, we suggest that oestradiol could be modulating osmoregulatory mechanisms on vasopressinergic magnocellular neurons, intensifying the local response of these cells to WD stimulus and consequently potentiating AVP secretion. Although the mechanism by which oestradiol could intensify the local response of the magnocellular neurons to hyperosmolality has not been established, Smejkalova and Woolley (2010) showed that oestradiol treatment potentiates glutamatergic synaptic transmission in hippocampal cells and that this effect is mediated by ER- $\beta$ but not by ER- $\alpha$. Considering that glutamatergic transmission is important to AVP secretion in response to osmotic stimulation (Sladek et al. 1998), this could be a possible mechanism by which oestradiol could intensify vasopressinergic neuronal activation, interacting with ER- $\beta$. However, future studies are needed to test this hypothesis.

Oestradiol treatment also increased the sensitivity for AVP secretion in response to hypovolemia induced by $\mathrm{WD}$, as demonstrated by the effect of oestradiol on the correlation between AVP and the haematocrit. Thus, it is possible that oestradiol modulates pathways related to volume and blood pressure. In this context, the literature shows that NTS and VLM (ventrolateral medulla) express oestrogen receptors (Shughrue et al. 1997, Simonian \& Herbison 1997). More specifically, A1 noradrenergic neurons, which innervate the vasopressinergic neurons of the SON and PVN, also express oestrogen receptors (Simonian \& Herbison 1997, Haywood et al. 1999). These data show that oestradiol has the potential to modulate afferent pathways of the NTS and VLM to SON and PVN. Our study provides data supporting a direct

Published by Bioscientifica Ltd 
action of oestradiol on magnocellular neurons, but based on these evidences from the literature we should also consider that during WD oestradiol might also affect brain pathways sensitive to hypovolemia and thereby increasing AVP secretion.

In summary, our results clearly demonstrated that oestradiol contributes to the maintenance of hydromineral homeostasis, which is disrupted in WD by both hyperosmotic and hypovolemic stimuli, modulating AVP secretion. The present study also suggests that the effects of oestradiol on AVP secretion seem not to occur at the transcriptional level but intensifying the local response to osmotic stimulation of vasopressinergic magnocellular neurons.

\section{Supplementary data}

This is linked to the online version of the paper at http://dx.doi.org/10.1530/ JOE-16-0311.

\section{Declaration of interest}

The authors declare that there is no conflict of interest that could be perceived as prejudicing the impartiality of the research reported.

\section{Funding}

This work was supported by the Fundaçao de Amparo a Pesquisa do Estado de Sao Paulo (FAPESP, \#2010/05436-3). Dr Mecawi is also funded by a High Impact Research grant from the University of Malaya (UM.C/625/1/ HIR/MOHE/MED/22 H-20001-E000086).

\section{Acknowledgements}

We thank Maria Valci dos Santos, Milene Mantovani, Lilian Eslaine and Rubens Fernando de Mello for their excellent technical assistance.

\section{References}

Aitken JM, Lindsay R \& Hart DM 1974 The redistribution of body sodium in women on long-term oestrogen therapy. Clinical Science and Molecular Medicine 47 179-187. (doi:10.1042/cs0470179)

Amico JA, Seif SM \& Robinson AG 1981 Oxytocin in human plasma: correlation with neurophysin and stimulation with estrogen. Journal of Clinical Endocrinology and Metabolism 52 988-993. (doi:10.1210/ jcem-52-5-988)

Amico JA, Crowley RS, Insel TR, Thomas A \& O'Keefe JA 1995 Effect of gonadal steroids upon hypothalamic oxytocin expression. Advances in Experimental Medicine and Biology 395 23-35.

Amico JA, Thomas A, Hollingshead DJ \& Kim NB 1997 Administration of long-term estradiol and progesterone followed by progesterone withdrawal does not alter the plasma oxytocin secretory response to cholecystokinin or the pituitary oxytocin content in ovariectomized rats. Endocrine Research 23 69-80. (doi:10.1080/07435809709031843)
Antunes-Rodrigues J, de Castro M, Elias LL, Valença MM \& McCann SM 2004 Neuroendocrine control of body fluid metabolism. Physiological Reviews 84 169-208. (doi:10.1152/physrev.00017.2003)

Araujo IG, Elias LL, Antunes-Rodrigues J, Reis LC \& Mecawi AS 2013 Effects of acute and subchronic AT1 receptor blockade on cardiovascular, hydromineral and neuroendocrine responses in female rats. Physiology and Behavior 122 104-112. (doi:10.1016/j. physbeh.2013.08.018)

Barron WM, Schreiber J \& Lindheimer MD 1986 Effect of ovarian sex steroids on osmoregulation and vasopressin secretion in the rat. American Journal of Physiology 250 E352-E361.

Botelho LM, Block CH, Khosla MC \& Santos RA 1994 Plasma angiotensin (1-7) immunoreactivity is increased by salt load, water deprivation, and hemorrhage. Peptides 15 723-729. (doi:10.1016/01969781(94)90103-1)

Brown CH, Bains JS, Ludwig M \& Stern JE 2013 Physiological regulation of magnocellular neurosecretory cell activity: integration of intrinsic, local and afferent mechanisms. Journal of Neuroendocrinology $\mathbf{2 5}$ 678-710. (doi:10.1111/jne.12051)

Caligioni CS \& Franci CR 2002 Oxytocin secretion induced by osmotic stimulation in rats during the estrous cycle and after ovariectomy and hormone replacement therapy. Life Sciences $712821-2831$. (doi:10.1016/S0024-3205(02)02139-2)

Carrazana EJ, Pasieka KB \& Majzoub JA 1988 The vasopressin mRNA poly(A) tract is unusually long and increases during stimulation of vasopressin gene expression in vivo. Molecular and Cellular Biology $\mathbf{8}$ 2267-2274. (doi:10.1128/MCB.8.6.2267)

Carter DA \& Murphy D 1989 Independent regulation of neuropeptide mRNA level and poly(A) tail length. Journal of Biological Chemistry 264 6601-6603.

Carter DA \& Murphy D 1991 Rapid changes in poly (A) tail length of vasopressin and oxytocin mRNAs form a common early component of neurohypophyseal peptide gene activation following physiological stimulation. Neuroendocrinology 53 1-6. (doi:10.1159/000125689)

Crofton JT, Baer PG, Share L \& Brooks DP 1985 Vasopressin release in male and female rats: effects of gonadectomy and treatment with gonadal steroid hormones. Endocrinology 117 1195-1200. (doi:10.1210/endo-117-3-1195)

Crowley RS \& Amico JA 1993 Gonadal steroid modulation of oxytocin and vasopressin gene expression in the hypothalamus of the osmotically stimulated rat. Endocrinology 133 2711-2718. (doi:10.1210/en.133.6.2711)

Crowley RS, Insel TR, O'Keefe JA \& Amico JA 1993 Cytoplasmic oxytocin and vasopressin gene transcripts decline postpartum in the hypothalamus of the lactating rat. Endocrinology 133 2704-2710. (doi:10.1210/en.133.6.2704)

Culman J, Baulmann J, Blume A \& Unger T 2001 The renin-angiotensin system in the brain: an update. Journal of the Renin-AngiotensinAldosterone System 2 96-102.

da Silveira LT, Junta CM, Monesi N, de Oliveira-Pelegrin GR, Passos GA \& Rocha MJ 2007 Time course of c-fos, vasopressin and oxytocin mRNA expression in the hypothalamus following long-term dehydration. Cellular and Molecular Neurobiology 27 575-584. (doi:10.1007/s10571007-9144-2)

Dalmasso C, Amigone JL \& Vivas L 2011 Serotonergic system involvement in the inhibitory action of estrogen on induced sodium appetite in female rats. Physiology and Behavior 104 398-407. (doi:10.1016/j.physbeh.2011.04.029)

Dalmasso C, Antunes-Rodrigues J, Vivas L \& De Luca LA Jr 2015 Mapping brain Fos immunoreactivity in response to water deprivation and partial rehydration: Influence of sodium intake. Physiology and Behavior 151 494-501. (doi:10.1016/j.physbeh.2015.08.020)

Davison JM, Gilmore EA, Dürr J, Robertson GL \& Lindheimer MD 1984 Altered osmotic thresholds for vasopressin secretion and thirst in human pregnancy. American Journal of Physiology 246 105-109. (doi:10.1152/ajpregu.00295.2000) http://joe.endocrinology-journals.org

DOI: 10.1530/JOE-16-0311
(C) 2016 Society for Endocrinology Printed in Great Britain 
De Luca LA Jr, Xu Z, Schoorlemmer GH, Thunhorst RL, Beltz TG, Menani JV \& Johnson AK 2002 Water deprivation-induced sodium appetite: humoral and cardiovascular mediators and immediate early genes. American Journal of Physiology: Regulatory, Integrative and Comparative Physiology 282 552-559.

Fitzsimons JT 1998 Angiotensin, thirst, and sodium appetite. Physiological Reviews 78 583-686.

Fujisawa S, Tanaka J \& Nomura M 2001 Estrogen attenuates the drinking response induced by activation of angiotensinergic pathways from the lateral hypothalamic area to the subfornical organ in female rats. Behavioural Brain Research 122 33-41. (doi:10.1016/S01664328(01)00176-0)

Gottlieb HB, Ji LL, Jones H, Penny ML, Fleming T \& Cunningham JT 2006 Differential effects of water and saline intake on water deprivation-induced c-fos staining in the rat. American Journal of Physiology: Regulatory, Integrative and Comparative Physiology 290 R1251-R1261. (doi:10.1152/ajpregu.00727.2005)

Greenwood MP, Mecawi AS, Hoe SZ, Mustafa MR, Johnson KR, Al-Mahmoud GA, Elias LLK, Paton JFR, Antunes-Rodrigues J, Gainer H, et al. 2015 A comparison of physiological and transcriptome responses to water deprivation and salt loading in the rat supraoptic nucleus. American Journal of Physiology: Regulatory, Integrative and Comparative Physiology 308 R559-R568. (doi:10.1152/ajpregu.00444.2014)

Haanwinckel MA, Antunes-Rodrigues J \& de Castro e Silva E 1991 Role of central beta-adrenoreceptors on stress-induced prolactin release in rats. Hormone and Metabolic Research 23 318-320. (doi:10.105 5/s-2007-1003686)

Hartley DE, Dickson SL \& Forsling ML 2004 Plasma vasopressin concentrations and Fos protein expression in the supraoptic nucleus following osmotic stimulation or hypovolaemia in the ovariectomized rat: effect of oestradiol replacement. Journal of Neuroendocrinology 16 191-197. (doi:10.1111/j.0953-8194.2004.01150.x)

Haywood SA, Simonian SX, van der Beek EM, Bicknell RJ \& Herbison AE 1999 Fluctuating estrogen and progesterone receptor expression in brainstem norepinephrine neurons through the rat estrous cycle. Endocrinology 140 3255-3263. (doi:10.1210/en.140.7.3255)

Hrabovszky E, Kalló I, Steinhauser A, Merchenthaler I, Coen CW, Petersen SL \& Liposits Z 2004 Estrogen receptor-beta in oxytocin and vasopressin neurons of the rat and human hypothalamus: immunocytochemical and in situ hybridization studies. Journal of Comparative Neurology 473 315-333. (doi:10.1002/cne.20127)

Huang W, Lee SL, Arnason SS \& Sjöquist M 1996 Dehydration natriuresis in male rats is mediated by oxytocin. American Journal of Physiology 270 R427-R433.

Husain MK, Fernando N, Shapiro M, Kagan A \& Glick SM 1973 Radioimmunoassay of arginine vasopressin in human plasma. Journal of Clinical Endocrinology and Metabolism 37 616-625. (doi:10.1210/ jcem-37-4-616)

Kisley LR, Sakai RR \& Fluharty SJ 1999 Estrogen decreases hypothalamic angiotensin II AT1 receptor binding and mRNA in the female rat. Brain Research 844 34-42. (doi:10.1016/S0006-8993(99)01815-6)

Krause EG, Curtis KS, Davis LM, Stowe JR \& Contreras RJ 2003 Estrogen influences stimulated water intake by ovariectomized female rats. Physiology and Behavior 79 267-274. (doi:10.1016/S00319384(03)00095-7)

Krause EG, Curtis KS, Stincic TL, Markle JP \& Contreras RJ 2006 Oestrogen and weight loss decrease isoproterenol-induced Fos immunoreactivity and angiotensin type $1 \mathrm{mRNA}$ in the subfornical organ of female rats. Journal of Physiology 573 251-262. (doi:10.1113/ jphysiol.2006.106740)

Laflamme N, Nappi RE, Drolet G, Labrie C \& Rivest S 1998 Expression and neuropeptidergic characterization of estrogen receptors (ER $\alpha$ and ER $\beta$ ) throughout the rat brain: Anatomical evidence of distinct roles of each subtype. Journal of Neurobiology 36 357-378. (doi:10.1002/ (SICI)1097-4695(19980905)36:3<357::AID-NEU5>3.0.CO;2-V)
Livak KJ \& Schmittgen TD 2001 Analysis of relative gene expression data using real-time quantitative PCR and the 2(-Delta Delta C(T)) method. Methods 25 402-408. (doi:10.1006/meth.2001.1262)

Lucio-Oliveira F \& Franci CR 2012 Effect of the interaction between food state and the action of estrogen on oxytocinergic system activity. Journal of Endocrinology 212 129-138. (doi:10.1530/JOE-11-0272)

Mecawi AS, Lepletier A, Araujo IG, Fonseca FV \& Reis LC 2008 Oestrogenic influence on brain AT1 receptor signalling on the thirst and sodium appetite in osmotically stimulated and sodium-depleted female rats. Experimental Physiology 93 1002-1010. (doi:10.1113/ expphysiol.2008.042713)

Mecawi AS, Vilhena-Franco T, Araujo IG, Reis LC, Elias LL \& AntunesRodrigues J 2011 Estradiol potentiates hypothalamic vasopressin and oxytocin neuron activation and hormonal secretion induced by hypovolemic shock. American Journal of Physiology: Regulatory, Integrative and Comparative Physiology 301 R905-R915. (doi:10.1152/ ajpregu.00800.2010)

Mecawi AS, Ruginsk SG, Elias LL, Varanda WA \& Antunes-Rodrigues J 2015 Neuroendocrine regulation of hydromineral homeostasis. Comprehensive Physiology 5 1465-1516. (doi:10.1002/cphy.c140031)

Miller FD, Ozimek G, Milner RJ \& Bloom FE 1989 Regulation of neuronal oxytocin mRNA by ovarian steroids in the mature and developing hypothalamus. PNAS 86 2468-2472. (doi:10.1073/pnas.86.7.2468)

Morien A, Garrard L \& Rowland NE 1999 Expression of Fos immunoreactivity in rat brain during dehydration: effect of duration and timing of water deprivation. Brain Research 816 1-7. (doi:10.1016/S0006-8993(98)00828-2)

Oldfield BJ, Hards DK \& McKinley MJ 1991 Projections from the subfornical organ to the supraoptic nucleus in the rat: ultrastructural identification of an interposed synapse in the median preoptic nucleus using a combination of neuronal tracers. Brain Research 558 13-19. (doi:10.1016/0006-8993(91)90708-4)

Oliet SH \& Bourque CW 1993 Steady-state osmotic modulation of cationic conductance in neurons of rat supraoptic nucleus. American Journal of Physiology 265 R1475-R1479.

Paxinos G \& Watson C 1998 The Rat Brain in Stereotaxic Coordinates. San Diego, CA, USA: Academic Press

Rosas-Arellano MP, Solano-Flores LP \& Ciriello J 1999 Co-localization of estrogen and angiotensin receptors within subfornical organ neurons. Brain Research 837 254-262. (doi:10.1016/S0006-8993(99)01672-8)

Share L 1988 Role of vasopressin in cardiovascular regulation. Physiological Reviews 68 1248-1284.

Shughrue PJ, Lane MV \& Merchenthaler I 1997 Comparative distribution of estrogen receptor-alpha and -beta mRNA in the rat central nervous system. Journal of Comparative Neurology 388 507-525. (doi:10.1002/ (SICI)1096-9861(19971201)388:4<507::AID-CNE1>3.0.CO;2-6)

Simonian SX \& Herbison AE 1997 Differential expression of estrogen receptor and neuropeptide $\mathrm{Y}$ by brainstem A1 and A2 noradrenaline neurons. Neuroscience 76 517-529. (doi:10.1016/S03064522(96)00406-X)

Skowsky WR, Swan L \& Smith P 1979 Effects of sex steroid hormones on arginine vasopressin in intact and castrated male and female rats. Endocrinology 104 105-108. (doi:10.1210/endo-104-1-105)

Sladek CD, Badre SE, Morsette DJ \& Sidorowicz HE 1998 Role of non-NMDA receptors in osmotic and glutamate stimulation of vasopressin release: effect of rapid receptor desensitization. Journal of Neuroendocrinology 10 897-903. (doi:10.1046/j.13652826.1998.00276.x)

Smejkalova T \& Woolley CS 2010 Estradiol acutely potentiates hippocampal excitatory synaptic transmission through a presynaptic mechanism. Journal of Neuroscience 30 16137-16148. (doi:10.1523/ JNEUROSCI.4161-10.2010)

Stachenfeld NS, DiPietro L, Palter SF \& Nadel ER 1998 Estrogen influences osmotic secretion of AVP and body water balance in postmenopausal women. American Journal of Physiology 274 R187-R195. http://joe.endocrinology-journals.org

DOI: $10.1530 / J O E-16-0311$
(C) 2016 Society for Endocrinology Printed in Great Britain 
Stachenfeld NS \& Keefe DL 2002 Estrogen effects on osmotic regulation of AVP and fluid balance. American Journal of Physiology: Endocrinology and Metabolism 283 E711-E721. (doi:10.1152/ajpendo.00192.2002)

Stachenfeld NS \& Taylor HS 2004 Effects of estrogen and progesterone administration on extracellular fluid. Journal of Applied Physiology 96 1011-1018. (doi:10.1152/japplphysiol.01032.2003)

Stricker EM \& Sved AF 2002 Controls of vasopressin secretion and thirst: similarities and dissimilarities in signals. Physiology and Behavior $7 \mathbf{7}$ 731-736. (doi:10.1016/S0031-9384(02)00926-5)

Summy-Long JY \& Kadekaro M 2001 Role of circumventricular organs $(\mathrm{CVO})$ in neuroendocrine responses: interactions of $\mathrm{CVO}$ and the magnocellular neuroendocrine system in different reproductive states. Clinical and Experimental Pharmacology and Physiology 28 590-601. (doi:10.1046/j.1440-1681.2001.03491.x)

Swenson KL \& Sladek CD 1997 Gonadal steroid modulation of vasopressin secretion in response to osmotic stimulation. Endocrinology 138 2089-2097. (doi:10.1210/en.138.5.2089)

Tanaka J, Miyakubo H, Fujisawa S \& Nomura M 2003 Reduced dipsogenic response induced by angiotensin II activation of subfornical organ projections to the median preoptic nucleus in estrogen-treated rats Experimental Neurology 179 83-89. (doi:10.1006/exnr.2002.8054)

Thrasher TN 1994 Baroreceptor regulation of vasopressin and renin secretion: low-pressure versus high-pressure receptors. Frontiers in Neuroendocrinology 15 157-196. (doi:10.1006/frne.1994.1007)
Van Tol HH, Bolwerk EL, Liu B \& Burbach JP 1988 Oxytocin and vasopressin gene expression in the hypothalamo-neurohypophyseal system of the rat during the estrous cycle, pregnancy, and lactation. Endocrinology 122 945-951. (doi:10.1210/endo-122-3-945)

Veille JC, Morton MJ, Burry K, Nemeth M \& Speroff L 1986 Estradiol and hemodynamics during ovulation induction. Journal of Clinical Endocrinology and Metabolism 63 721-724. (doi:10.1210/jcem-63-3721)

Vilhena-Franco T, Mecawi AS, Elias LL \& Antunes-Rodrigues J 2011 Oestradiol potentiates hormone secretion and neuronal activation in response to hypertonic extracellular volume expansion in ovariectomised rats. Journal of Neuroendocrinology 23 481-489. (doi:10.1111/j.1365-2826.2011.02133.x)

Voisin DL, Simonian SX \& Herbison AE 1997 Identification of estrogen receptor-containing neurons projecting to the rat supraopitic nucleus. Neuroscience 78 215-228. (doi:10.1016/S03064522(96)00551-9)

Windle RJ, Forsling ML, Smith CP \& Balment RJ 1993 Patterns of neurohypophysial hormone release during dehydration in the rat. Journal of Endocrinology 137 311-319. (doi:10.1677/joe.0.1370311)

Zingg HH \& Lefebvre DL 1989 Oxytocin mRNA: increase of polyadenylate tail size during pregnancy and lactation. Molecular and Cellular Endocrinology 65 59-62. (doi:10.1016/03037207(89)90165-2)

Received in final form 1 September 2016

Accepted 9 September 2016

Accepted Preprint published online 9 September 2016
C) 2016 Society for Endocrinology Printed in Great Britain
Published by Bioscientifica Ltd 